\title{
El imaginario de lo chino en las revistas magazinescas chilenas de principios del siglo $X^{1}$ The imaginary of Chineseness in Chilean magazines of the early XX century
}

Fecha recepción: octubre 2020 / fecha aceptación: enero 2021

María Elvira Ríos², María Montt ${ }^{3}$ y Carol Chan ${ }^{4}$

DOI: https://doi.org/10.51188/rrts.num24.434

\begin{abstract}
Resumen
El aniversario de los cien años de Independencia de Chile, en 1910, remarcó el triunfo de la libertad nacional para el país, pero también un desafío para la modernización y la construcción de identidad. El mayor desarrollo de los medios de comunicación y la opinión pública se combinó con debates intelectuales por discutir una identidad chilena, proceso que reveló las tendencias e influencias sobre la concepción de lo otro. En ese contexto encontramos las revistas magazinescas en las que, según se propone en este artículo, es posible identificar el imaginario chino disponible en el periodo. Una revisión de estas revistas durante la primera mitad del siglo XX evidencia la presencia de estereotipos que permearon transversal y profundamente en la sociedad y que aún persisten en Chile contemporáneo.
\end{abstract}

Palabras clave: lo chino; identidad; medios; América Latina; representación.

\footnotetext{
1 Este texto fue financiado por ANID Fondecyt, Postdoctorado № 3190076 y ANID Fondecyt Iniciación № 11200151 .

2 Doctora, Centro de estudios de Asia y África, El Colegio de México. Postdoctorado ANID Fondecyt N 3190076, Facultad de Filosofía, Instituto de Estética, Pontificia Universidad Católica de Chile. Avda. Jaime Guzmán Errázuriz 3300. Santiago, Chile. Email: mariaelvira.rios.p@gmail.com

3 Doctora en Estudios Culturales Latinoamericanos, Universidad de Manchester. Profesora Instituto de Historia, miembro del Centro de Estudios Asiáticos, Pontificia Universidad Católica de Chile. Avda.Vicuña Mackenna 4860, Santiago, Chile. Email: mumontt@uc.cl

4 Doctora en Antropología, Universidad de Pittsburgh. Profesora Universidad Academia de Humanismo Cristiano. Av. Condell 343, Santiago, Chile. Email: carolchanzilin@gmail.com
} 


\begin{abstract}
The 100th anniversary of Independence in 1910 marked a triumph of national freedom for Chile, but the country faced many challenges regarding its modernization and identity construction. The development of mass media and public opinion combined with intellectual discussions in debates over Chilean identity. This process is revealing of the tendencies and influences regarding the notion of the other. In this context, we find magazines where, as this article proposes, it is possible to find certain elements of the Chinese imaginary of the period. An examination of these magazines that circulated during the first half of the twentieth century reveals the presence of stereotypes that permeated and have endured in Chilean society.
\end{abstract}

Keywords: Chineseness; identity; media; Latin America; representation.

En la constante reconstrucción de la identidad chilena y en medio de la pandemia del COVID-19 que impactó al mundo en 2020, emergen aprensiones de antaño hacia "lo chino". En discursos públicos u opiniones expresadas en diversos espacios por la elite, periodistas, políticos u otros hallamos una retórica racista de rechazo, con aspectos caricaturescos: "lo chino" como sinónimo de lo "asiático", lo chino como lo sucio, lo ignorante, lo raro (Chan y Montt Strabucchi, 2020b; Montt Strabucchi, 2017; Min, 2020). Durante la pandemia de COVID-19, lo que ocurrió en Chile fue similar a lo que sucedió con las minorías asiáticas (en muchas ocasiones referidas como "orientales") en otros lugares, donde la sociedad volvió a caer en sus peores patrones de prejuicio (Wang, Chen, Li, Luu, Yan y Madrisotti, 2020). A pesar de que es posible encontrar esfuerzos de cineastas, escritores, artistas y músicos chilenos que desafían las dicotomías, problematizando la identidad nacional o "étnica" chilena (ver Chan y Montt Strabucchi, 2020a), la pandemia de COVID-19 fortaleció las ideas sobre las personas chinas y lo chino en general como algo externo a Chile, revelando la naturaleza frágil y superficial de los recientes intentos sancionados por el gobierno de articular a Chile como una nación global, multicultural y diversa (Chan y Montt Strabucchi, 2020b, p.15). La pandemia global de COVID-19 ha provocado el resurgimiento de viejos discursos racistas e ideas que ubican a los chinos o asiáticos de manera similar al pasado, asociadas con la suciedad y amenazando la democracia y la libertad "occidental" de Chile. Los ejemplos son diversos, entre ellos, el programa de televisión "Morandé con compañía” donde se vincula, culpa y se denigra vulgarmente a las personas chinas por la pandemia (Chan y Gómez, 2020), parodias en memes o anuncios anti chinos en Villa Alemana, combinando percepciones acerca de la mala calidad de sus productos, la tecnología, atraso y poca higiene y la crueldad (ver Chan y Montt Strabucchi, 2020b). Estas últimas se presentan como ideas disponibles previo a la aparición de COVID-19.

Al concentrarnos en la primera mitad del siglo $X X$, hallamos el papel fundamental que cumplieron las revistas magazinescas 5 chilenas en la articulación del imaginario chino (Ossandón y Santa Cruz, 2005). Por medio de estas revistas, la sociedad se encuentra con la existencia de un producto nacional, que relata

5 Utilizamos el término magazinescas, siguiendo a Ossandón y Santa Cruz (2005). 
historias, anécdotas, curiosidades, cuentos o noticias, en ocasiones acompañados por caricaturas o fotografías.

Para aquella época, el número de seguidores de los principales semanarios de la actualidad, Sucesos y Zig-Zag, crecía. La revista Sucesos, fundada en Valparaíso el 18 de agosto de 1902 por los hermanos Gustavo y Alberto Helfmann, destacaba por sus caricaturas y artículos satíricos. Zig-Zag, fundada por el editor del periódico El Mercurio, Agustín Edwards Mac Clure, era una revista ilustrada que cubría diversos tópicos, en la cual las noticias políticas se leían entre avisos publicitarios, noticias sociales, internacionales y otras variedades de textos. El grupo de lectores de ambas publicaciones era amplio y heterogéneo, con una circulación de más de treinta mil ejemplares (Rinke, 2002, p.41). Zig-Zag se convirtió en una de las revistas más destacadas e influyentes de la historia de la cultura impresa chilena y de las más leídas entre la población (Dussaillant y Urzúa, 2020, p.11).

La importancia que adquieren estas revistas se debe, principalmente, a la transformación comunicacional y, por lo tanto, cultural, en que se expresan las "nuevas visibilidades o exterioridades sígnicas" (Ossandón y Santa Cruz, 2005, p.11). En lo que respecta a China, la información que estas revistas nos proporcionan varía entre cuestiones históricas, culturales y sociales. La información internacional la obtenían del mercado de las agencias de noticias de Estados Unidos: la United Press y Associated Press; las que habían reemplazado a los competidores europeos durante la Primera Guerra Mundial. Un cable submarino de la All America Cable Company proveía a los periódicos líderes entre trescientas y dos mil palabras de noticias internacionales (Rinke, 2002, p.43). De varias de las noticias o textos que se referían al mundo exterior se desconocía su autor o procedencia, dejando en evidencia la permeabilidad de estos apartados.

Tanto la migración china a América como el contexto político del país asiático serán los escenarios en el que se desarrollan los imaginarios que lograrán adentrarse y perdurar a tal punto en la sociedad chilena que pareciera que lo escrito, hace ya más de cien años, lo estuviéramos leyendo ahora, en el siglo XXI, con la pandemia. Esto es posible de ver en los siguientes ejemplos:

\section{Semanitas}

iPero, cuántas cosas se ven en Chile, digo yo, que no se ven en parte alguna del mundo! O por mejor decir icuántas se hacen en esta bendita tierra de poetas, oradores y buenos municipales, que se hacen al revés en otras partes!

Todavía no se nos sale del cuerpo el susto de la bubónica cuando ya se vislumbra otra plaga, peor que esa, irrefragablemente peor.

Porque después de todo, si se asean los conventillos, si se ordena el cambio de cazzetas en el Teatro Nacional, la bubónica se irá tal como vino: con deseos de hacer algo. Pero no sucede así con los 50,000 compales que están por venirse sobre nosotros. 
¡50,000! Es poca cosa ¿̇erdad? iPoca! la mitad de nuestra población, nada menos.

El Gobierno, interesado en la inmigración, tiene en vista la traída de esos copalitos cuya industria cree que aún hace falta en Chile...!

iNada! Que los latones, los gatos y otros animalejos por el estilo serán en adelante el plato obligado, y la lengua, es decir el idioma japonés, el más preciso, indispensable y necesario...

(Sucesos, Semanario Ilustrado de Actualidades Año II. Valparaíso, Octubre 3 de 1903).

\section{La elegancia en China}

La guerra de Oriente ha proyectado su interés sobre el lejano país del extremo Oriente, que parecía subyugado y que de repente se levanta rejuvenecido súbitamente, y como por obra de encantamiento. Es todo un mundo misterioso y cerrado que se alza mostrándonos una civilización que surge a través de los siglos y de las más remotas épocas de la historia. Nada más curioso que penetrar en las intimidades de esa vida, asistiendo a la jornada de una dama elegante, con las relaciones complicadas establecidas por los lazos de las costumbres...

(Zig-Zag, 23 de septiembre de 1911).

Por una parte, su lectura nos traslada a lo que circuló en cientos de anuncios, noticias y memes durante la expansión del virus Covid 19. Por otra parte, es evidente la perspectiva orientalista y exótica sobre la elegancia y sofisticación china, que en un pasado trasladaba consigo el tono misterioso y de asombro a la cultura china y que hoy es reemplazada por la admiración a su tecnología y la oportunidad de negocio con el país asiático. El primer texto de "Semanitas" escrito en 1903, reúne los aspectos característicos de una sociedad que teme al "peligro amarillo", alimentada de las ideas presentes en Estados Unidos de la época y donde no hay distinción entre lo chino y otras culturas del Asia. Esto, en un contexto de construcción de una sociedad moderna, cuya identidad tambaleaba entre lo que se suponía que debía ser la "identidad chilena", concepto creado a partir de una serie de estereotipos en donde el asiático nunca estuvo. $\mathrm{O}$, en otras palabras, en un contexto donde "lo chino" no figura como parte de la identidad chilena, y siempre más bien como algo ajeno y lejano, y sin considerar la migración histórica de ciudadanos chinos a Sudamérica. De lo anterior nos preguntamos: ¿Qué ideas sobre lo chino contribuyeron los medios de comunicación de masas de principios de siglo? ¿Desde qué perspectivas la percepción de lo chino responde a una idea de esencialismo en la construcción de identidad chilena?

En este texto pretendemos indagar acerca del imaginario chino por medio de las primeras revistas magazinescas chilenas de alta circulación durante la primera mitad el siglo XX, en un periodo en donde la sociedad iba articulando una posición propia relativa a la modernidad (Silva, 2018). Se analizan aquí, a través de una revisión de varios números publicados entre 1903 y 1937, los elementos visuales y 
textuales que dialogan con los aspectos orientalistas, la manifestación de otredad como "extraño" (Ahmed, 2000), de esa China como término o figura híbrida (Montt Strabucchi, 2017), contextualizado en los sucesos políticos y sociales de ambos países.

Ahmed explica que los sujetos son reconocidos como "extraños" a través de encuentros con otros y, por lo tanto, la existencia del sujeto no puede separarse de los "otros" con los cuales se encuentran. A esto agrega que, al enfrentarnos a los demás, buscamos reconocer quiénes son esos otros, leyendo los signos en su cuerpo o su cuerpo como un signo, lecturas que constituyen "el sujeto" en relación con "lo extraño" (2000, p.7-8). Nuestra propuesta, y construyendo sobre la idea de "lo extraño" de Ahmed, es que los textos, caricaturas y fotografías de las revistas que analizaremos serán las primeras imágenes narrativas y visuales de lo chino para gran parte de la población chilena de entonces. Por esto, descrito e interpretado por estos medios nos encontramos con ese "otro" de Ahmed. En este sentido, más que un encuentro directo, "face to face" con lo chino, estas imágenes llevan a la construcción del imaginario de lo chino. Desde esas imágenes la sociedad chilena recrea un encuentro imaginario, con el que reconstruye al "extraño". Son estas representaciones las que contribuyen a delinear a este "otro" chino que perdura incluso en las representaciones contemporáneas. Aunque en la actualidad es posible hallar reproducciones culturales que problematizan estos estereotipos, lo que se propone en este artículo es señalar los orígenes históricos y la continuidad de este imaginario de lo chino.

\section{Lo moderno y el boom de los medios}

La modernización del siglo XIX fue, básicamente, una carrera por aumentar y aumentar el comercio externo: más exportaciones, más importaciones (...). El modelo ideal de modernidad era claramente ejemplificado por las democracias occidentales, en especial la de Estados Unidos (...) Lo que no concordaba con aquel modelo que era visto necesariamente como deficiente (Rinke, 2002, p.16-22).

A principios del siglo XX la sociedad chilena aspiraba a una sociedad moderna, que requería de luz eléctrica, de transporte, infraestructura, industrialización, explotación de los recursos naturales para agilizar la economía, mejoras en la educación y viviendas sociales, entre otras acciones (ver Silva, 2008). El sujeto chileno habitaba un tiempo y espacio que continuamente buscaba encajar con ese imaginario del ser moderno occidental, el que se nutría con la interacción de representaciones ideológicas dominantes (catolicismo, nacionalismo) y, aludiendo a Saurabh Dube (2017), cargadas de producciones diarias de espacio y tiempo como "constituyentes de las convenciones sociales y las prácticas históricas que las apuntalan y, a la vez, están conformadas por ellas", que son componentes claves y consecutivos de la definición de los mundos sociales y sus divisiones (Dube, 2017, p.495).

En el inicio de un nuevo siglo, entre el vaivén de las contradicciones a lo civilizado, lo moderno y lo identitario de un pueblo chileno y el sesgo euro centrista 
e imaginario estadounidense que invita al desarrollo, brotan las comunicaciones de masas. En palabras de Rinke,

Los chilenos vivieron el surgimiento de las comunicaciones de masas y de una sociedad de masas a la par que se redefinía el discurso nacionalista, en parte reflejado en reformas iniciadas o al menos acompañadas por un Estado que descubría su rol interventor durante este periodo (Rinke, 2002, p.23).

Será en el surgimiento de aquellos medios visuales, el que va a la par con la búsqueda de la identidad y la opinión pública, en que las revistas ilustradas, suplemento y competencia de los periódicos tradicionales, adquieren un papel fundamental.

En la búsqueda del nacionalismo y la identidad, líderes políticos e intelectuales sacan la voz en publicaciones como Raza chilena (1904) de Nicolás Palacios, El roto (1927 cuarta edición) de Joaquín Edwards Bello o en las ideas de personajes como el político Enrique Mac-Iver, el escritor Tancredo Pinochet Le-Brun, Carlos Keller, Domingo Melfi, Francisco A. Encina, Alberto Cabero o Ricardo A. Latcham, entre otros. Entre las críticas a la elite por adaptarse a modelos de desarrollo extranjero y a quienes levantaban la imagen de los "araucanos" como orgullo racial (Rinke, 2002, p.119-126), se palpaba el "trajín" intelectual, en el que imperaba un imaginario estereotipado y un sesgo a la herencia cultural e identidad indígena. En ese ir y venir el ser asiático no entraba en la discusión y si lo hacía no era en términos positivos, como podemos observar en el siguiente ejemplo: “...con negros, mulatos, y mercaderes chinos no se forma una gran nacionalidad” (de Valdivia 1929, p.68). A pesar de la demanda de la mano de obra china barata que se produce entre mediados y fines del siglo XIX, la presencia china en los países latinoamericanos se consideraba indeseable (Hu-Dehart, 1994; López, 2016; Palma y Ragas, 2018; Chan y Montt Strabucchi, 2020a), algo que también se evidencia en la Ley de Colonización de 1845 y la exclusión de países árabes y asiáticos (Cano y Soffia, 2009, p.48).

En este sentido, las personas chinas se excluían de las discusiones sobre ciudadanía. Por ejemplo, Engin F. Isin analiza el concepto de "ciudadano" y se detiene en el análisis de Walter Mignolo (2003, p.452) sobre modernidad y colonialidad como dos lados de la misma moneda (Isin, 2012, p.565) y sobre la perspectiva orientalista en torno al sujeto colonizado. En la época del Chile que aquí nos atañe y a partir del contexto específico entregado por el público que leía estas revistas de circulación masiva, es posible observar una articulación de identidad personal y nacional desde la concepción de lo moderno, excluyendo a aquel "otro" que no tiene cabida en la construcción de una sociedad civilizada, moderna y occidental. Como recalca Rita Segato (2007) y se destacará en el estudio acerca de las personas migrantes colombianas y la resignificación de la alteridad en el Chile actual (Stang y Solano, 2017), la formación de lo nacional o una nación presenta aspectos racistas, prejuicios y la discriminación étnica de un orden particular y construidas en la historia propia (Stang y Solano, 2017, p.3).

La bajada de estos aspectos nacionalistas a la sociedad, que ya se venían construyendo desde la segunda mitad del siglo XIX, se efectúa durante la 
presidencia del coronel Carlos Ibáñez del Campo (1927-1931). En este periodo se enfatiza el esfuerzo por construir el nacionalismo en el discurso político. La retórica nacionalista creó expectativas demasiado altas y destinadas a frustrarse producto de la evidente dependencia del conocimiento y los capitales foráneos. Con frecuencia, el proyecto nacionalista de lbáñez debió ceder terreno por la necesidad de préstamos extranjeros (Rinke, 2002, p.130-152). Sin embargo, esto no opaca las concepciones que continuaron elaborándose sobre la identidad chilena, elevando una idea de una raza blanca.

\section{Lo chino en Revista Sucesos y Zig-Zag}

Las representaciones estereotipadas de las personas chinas en Chile circularon en diversos medios y expresiones culturales durante el siglo XX. Famoso es, por ejemplo, el cómic de Chu Man Fu de Jorge Christie Mouat, cuyo nombre alude al villano Fu Man-Chú, personaje que provenía de una novela escrita por Sax Rohmer y fue muy popular en películas de la época (Rojas Flores y García Castro, 2014; Chan y Montt Strabucchi, 2020a). Ya desde principios de siglo es posible encontrar figuraciones estereotipadas de personas chinas en las revistas chilenas que hemos analizado, entre 1900 y 1940, en un contexto marcado por racismo en las representaciones de China. El contexto político chino también contribuirá a elevar los estereotipos en las revistas, decorada con los aspectos del orientalismo, que serán una constante durante el periodo.

\section{Migración de chinos a Chile}

Dentro del contexto ambivalente en los Estados Unidos hacia los sujetos americanos nativos, hispanos, africanos, entre otros, la idea de "peligro amarillo" contribuyó a la noción de que todas las personas no blancas eran física e intelectualmente inferiores, de dudosa moral, paganas, promiscuas, ocasionadoras de enfermedades, violentas, salvajes, no civilizadas y con la necesidad de ser guiadas por personas consideradas blancas. Este concepto se instaló en la imaginación popular norteamericana entre finales del siglo XIX y principios del XX, en la creación de los medios de masa (Marchetti, 1993, p.3) y luego se traslada a los países de América Latina. En este contexto, y alimentado por discursos internacionales, se articulaba y trasladaba a la región la noción del "peligro amarillo". Las noticias acerca del "peligro amarillo" tomaron significancia local cuando se inician las protestas contra la inmigración china en el norte de Chile.

Serán estas percepciones la que se grafican verbal y visualmente en las revistas. En ellas se manifiestan el estereotipo imaginario ya nutrido por Estados Unidos y los demás países de América que habían recibido a chinos trabajadores en los ferrocarriles, minas y guaneras desde finales del siglo XIX:

En lquique se ha celebrado un gran meeting para protestar contra la inmigración china.

El obrero nacional es caro y regalón. La entrada súbita de diez mil colíes que no comen, ni gustan, ni consumen nada, es una amenaza. Igual amenaza es la que tiene un gato doméstico que bebe leche, come 
carne, y se acuesta sobre la alfombra, ante la llegada de un quique chileno que no se alimenta sino con ratones, y se pasa todo el día enojado... como quique, en un rincón del último patio. Los salitreros importarán seguramente los chinos que necesitan. Pero se me ocurre que los infelices van a pasar mal rato... (Zig-Zag, 12 de mayo de 1907).

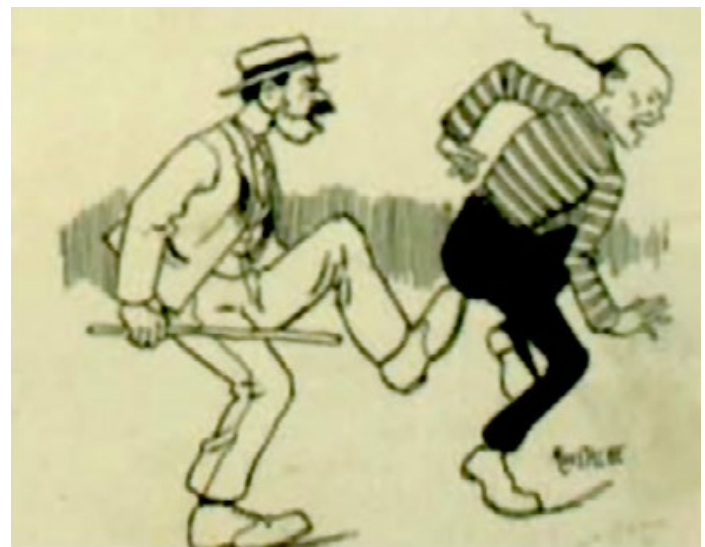

Caricatura de Moustache. Zig-Zag, 12 de mayo de 1907.

Aquí se compara a los chinos con el quique, un animal carnívoro sudamericano, conocido por cazar, entre otros animales, a ratones y ser muy agresivo. No sólo se trata de racismo en este caso sino también de considerar a los chinos como aquel que viene a quitar el alimento a los más débiles (representado por un gato doméstico) y sumado a ello, de mal carácter. El imaginario del chino como aquel que se alimenta de animales desgraciados de la calle será una de las características que más se querrá enfatizar de forma sarcástica y burlesca en las caricaturas de la época.

Uno de los espacios donde podemos notar este imaginario de lo chino es en representaciones visuales. En las revistas se observa cómo el dibujo asume diferentes usos, siendo el género de la caricatura el que se instala con fuerza en los medios de prensa chilenos, sobre todo, por su carácter provocador. Entre las opiniones de la comunidad intelectual liberal sobre las caricaturas se lee la siguiente opinión del periodista y escritor José Antonio Torres: "el objeto de la caricatura es corregir las costumbres i los defectos, es satirizar, poner en ridículo si se quiere, aquello que se manifiesta ridículo para procurar su corrección”. Finalmente, Torres invitaba en su texto a aceptar, tal como se hacía en Europa, la caricatura, pues era necesario "que acabemos de una vez de civilizarnos" (Herrera Styles y Zamorano Pérez, 2019, p.172-174).

Entre los caricaturistas de la época y de quienes hallaremos dibujos de hombres chinos, destaca Julio Bozo (1879-1942), cuyo seudónimo es Moustache. Colaborador en varias publicaciones como Instantáneas, Corre Vuela y Zig-Zag, entre otras, fue uno de los dibujantes más influyentes de las primeras décadas del siglo $X X$ y desarrolló un estilo de caricatura en el que se reía de diversos temas de la realidad local (Herrera Styles y Zamorano Pérez, 2019, p.187). Sobre el "peligro 
amarillo" y proyectando la preocupación de amenaza para los chilenos del norte que recibían a los chinos culíes a trabajar en las minas, hallamos caricaturas que Moustache dibujó, como la que se observa a continuación:

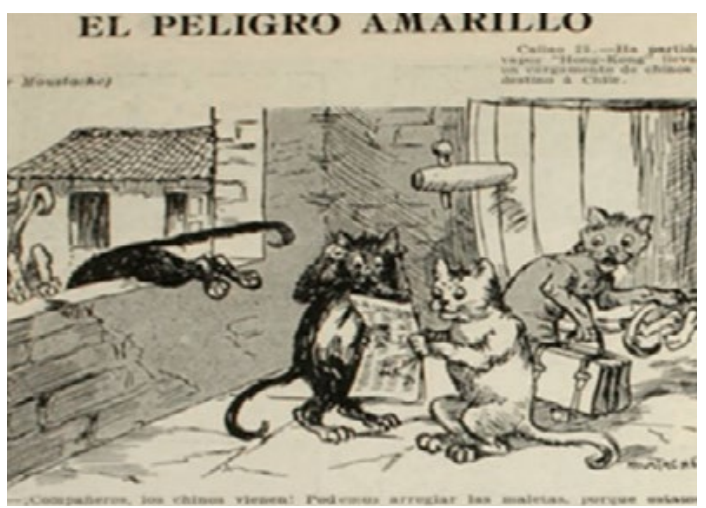

Callao 25. - Ha partido el vapor "Hong-Kong" Ilevando un cargamento de chinos con destino a Chile.

iCompañeros, los chinos vienen! Podemos arreglar las maletas, porque estamos demás en este país. (Zig-Zag, 31 de julio de 1909)

Como podemos notar, la utilización de la palabra "cargamento" habla por sí misma: la ilustración claramente no sólo corresponde a la caricatura de los gatos escapando de la ciudad sino que da cuenta de una concepción hacia el chino como una carga y, en tanto carga, un ser prácticamente inhumano.

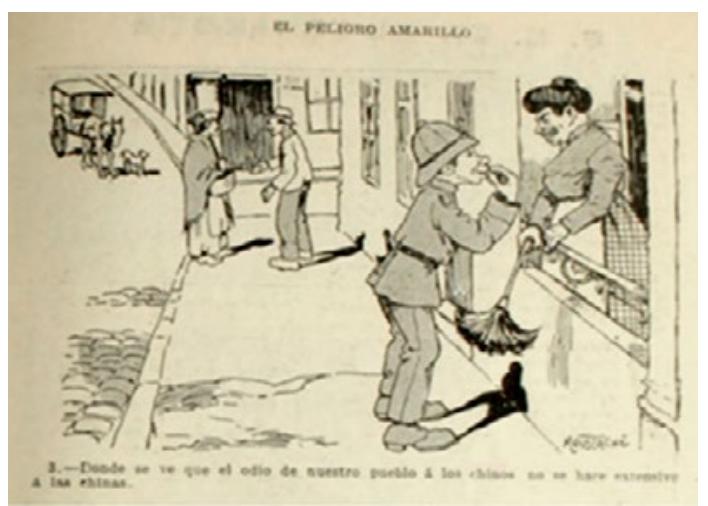

Donde se ve que el odio de nuestro pueblo a los chinos no se hace extensivo a las chinas. (Zig-Zag, 31 de julio de 1909)

En esta última caricatura, Moustache juega con la denominación de "los chinos" y "las chinas", lo que nos traslada al uso de la palabra "chino/a" en la América colonial. Para aquel entonces, lo chino se utilizaba para hacer referencia a aquella persona con orígenes étnicos diversos, de estrato social inferior y que trabajaba en la servidumbre. Esta última acepción se cree que deriva fonéticamente de la palabra quechua čína, hembra, sirvienta (RAE, 2019). De esto se deduce lo que investigadores ya han señalado con respecto a la palabra chino/a, su concepción como sinónimo de lo asiático en la España colonial en América Latina, su utilización 
para referirse a la mezcla de razas y, sin lugar a dudas, de carácter inferior en la sociedad (Siu, 2007; Seijas, 2015; Montt Strabucchi, 2017).

\section{Fin del imperio e inicio de la República}

La mirada hacia un imperio que se desvanecía se hizo notar en los medios internacionales. Las noticias que las revistas magazinescas obtienen de los reportes extranjeros apuntan a los procesos bélicos y al contenido violento de los sucesos relatados sobre el fin del imperio Qing. La violencia desatada en China se elevará hasta el punto de combinar el imaginario del "suplicio chino" con acontecimientos específicos que se vivían en el país, donde la caricatura es combinada con la ironía de anuncios publicitarios.

Moustache, junto con Joaquín Díaz Garcés y Guillermo González Echenique, fundaron en abril de 1900 la revista Instantáneas, con el subtítulo Semanario Festivo, Literario, Artístico y de Actualidades (Mejías Alonso y Clemente San Román, 2018, p.581). En esta revista se promocionaba el Té 18, producto cuya gráfica la creaba el ilustrador Alejandro Faure, pero que en la siguiente imagen veremos que el autor será un tal John Bull (posiblemente seudónimo), ilustrador de relatos y cuentos cortos. Bull interpreta en su dibujo un episodio satírico del suplicio del ministro ruso en China y su señora, en el contexto de las relaciones con las potencias internacionales en la Guerra de los Bóxers (Mejías Alonso y Clemente San Román, 2018, p.587-588). En ella observamos la práctica de castigos y matanzas violentas combinadas con la estética orientalista con una pagoda detrás (que irónicamente simboliza el budismo, cuyo fundamento es ahims $\bar{a}$, la no violencia), un funcionario vestido en un estilo tradicional "chino-japonés", con un abanico, quitasol de bambú y un sable. Finalmente, una de las cabezas ensangrentadas en el suelo, balbuceando sus últimas palabras, diciendo: "Declaro antes de morir que el Té 18 es el mejor".

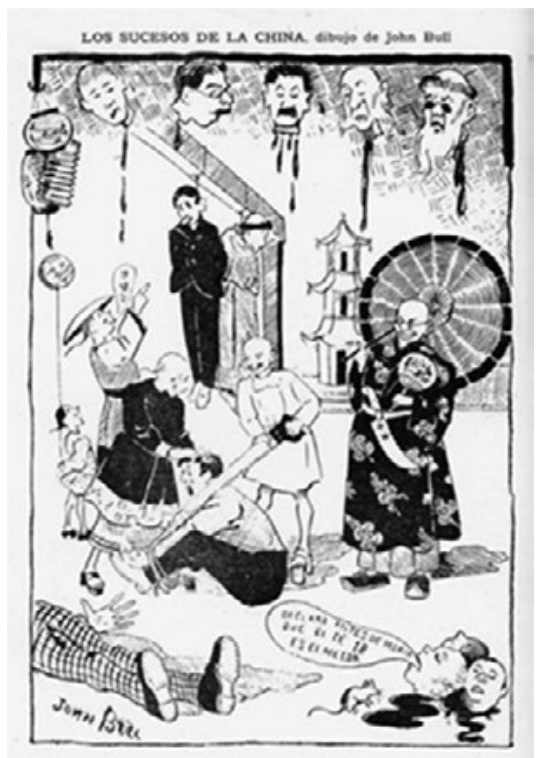

Instantáneas, 22 de julio de 1900. 
El sarcasmo se verá en un contexto histórico y político casi diez años después, en 1911, cuando la mirada hacia China, enfatizaba la finalización del imperio y el inicio de la modernización del país por medio de un estado republicano:

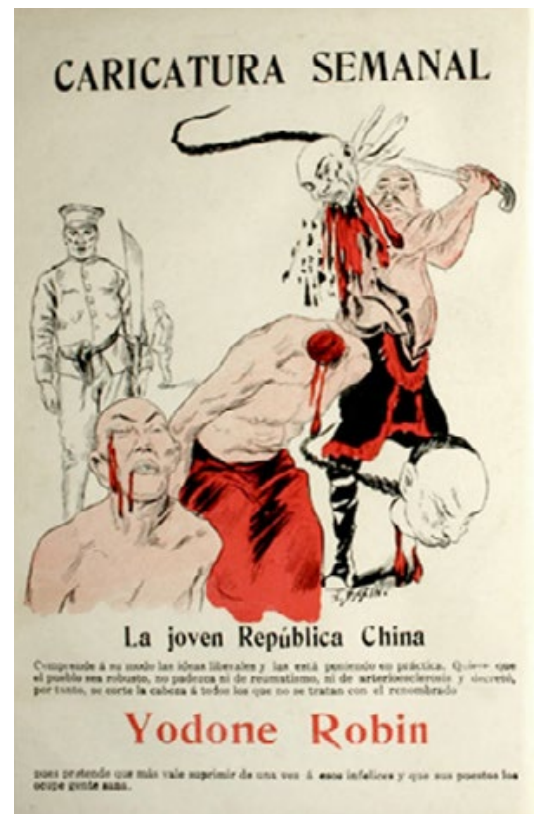

Zig-Zag, 13 de abril de 1912.

La joven República China

Comprende a su modo las ideas liberales y las está poniendo en práctica. Quiere que el pueblo sea robusto, no padezca ni de reumatismo, ni de arterioesclerosis y decretó, por tanto, se corte la cabeza á todos los que no se tratan con el renombrado YODONE ROBIN pues pretende que más vale suprimir de una vez á esos infelices y que sus puestos los ocupe gente sana. (Zig-Zag, 13 de abril de 1912).

En esta ilustración firmada por un tal X. Garín, de la revista Zig-Zag, se observa el acto brutal del corte de cabeza de un chino manchú, simbolizando el fin del Imperio Qing y detrás a un soldado republicano, sosteniendo un sable. En aquella época, la propaganda comercial de Yodone Robin, una medicina que se utilizaba para la arterio-escleorosis, asma, sífilis, reumatismo y obesidad, solía combinar a personajes de la época, como también a episodios sociales o políticos del momento, con el anuncio sarcástico del uso de la medicina.

Dentro de esta época de fin del imperio, inicio de la República y la modernización de China, encontramos nuevamente la caricatura de Moustache, esta vez ilustrando un episodio que dice relación con los exámenes imperiales: 


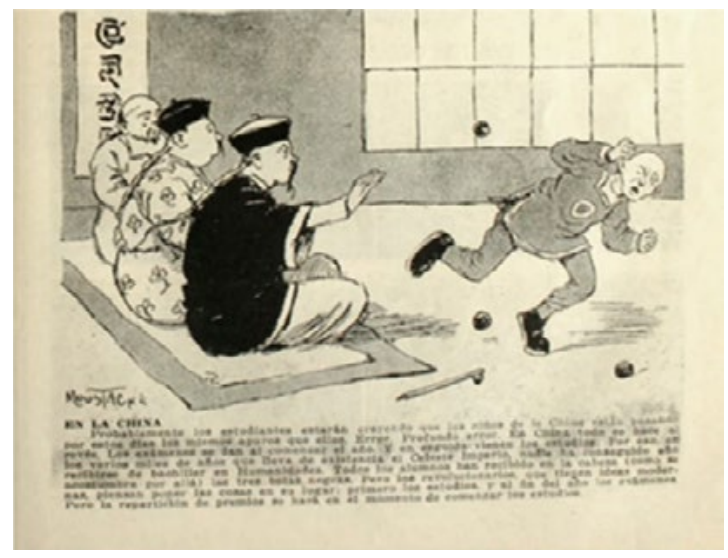

En la China

Zig-Zag, 30 de diciembre de 1911.

Probablemente los estudiantes estarán creyendo que los niños de la China están pasando por estos días los mismos apuros que ellos. Error. Profundo error. En China, todo se hace al revés. Los exámenes se dan al comenzar el año. $Y$ en seguida vienen los estudios. Por eso, en los varios miles de años que lleva la existencia el Celeste Imperio, nadie ha conseguido aún recibirse de bachiller en Humanidades. Todos los alumnos han recibido en la cabeza (como se acostumbra por allá) las tres bolas negras. Pero los revolucionarios, que tienen ideas modernas, piensan poner las cosas en su lugar: primero los estudios, y al fin del año los exámenes. Pero la repartición de premios se hará en el momento de comenzar los estudios. (Zig-Zag, 30 de diciembre de 1911)

En esta caricatura se observa una ilustración que combina a un imaginario chino-japonés, de maestros del imperio sentados en una alfombra tipo tatami, con batas y unos garabatos colgados en la pared, simulando la escritura china. Además de la caracterización del castigo con las tres bolas negras que lanzan al estudiante, se manifiesta el desconocimiento sobre la decisión del término del examen imperial, previo a la República. La llegada de las personas extranjeras a China, la guerra del opio y la guerra sino-japonés afectará sobremanera en la decisión de cambiar el sistema educacional de China y serán Kang Youwei y Liang Qichao los que influyeron en el emperador Guangxu para la abolición del examen en 1905 (Feng, 1995, p.35-36); no obstante, como podemos ver, este tipo de información excede lo que en Chile se informaba sobre China en la época. En este sentido, la asociación de lo chino a la tradición y lo tradicional aparece eclipsando la información veraz sobre los procesos políticos y reformas modernizadoras en China.

No obstante, si bien se consideraba una necesidad la llegada de la modernidad occidental a China, también hallamos comentarios en los que se manifiesta una preocupación sobre la modernización del país, combinando los beneficios entregados por los occidentales a China versus la potencia y amenaza para el futuro que un "despertar" de China significaría. Al respecto, en febrero de 1908, la revista Zig - Zag publica un texto titulado "El despertar de un imperio", en el que 
se destaca la llegada del primer ferrocarril al país y, paralelamente, se presagia el "peligro amarillo" con los nuevos avances tecnológicos:

La locomotora es la primera innovación civilizadora adoptada por esa raza. En pos de ella vendrán sin duda muchas otras y se sucederán con rapidez asombrosa hasta que llegará un día en que el mundo al despertar se encontrará con la sorprendente nueva de que allá en el extremo oriente, junto al valeroso pueblo japonés, otra nación se ha levantado poderosa y se ha encumbrado a rejiones [sic] desde donde puede hacer temblar al mundo de los blancos. El día aquel tardará pero llegará. $Y$ entonces esos mismos beneficios que con tanto esfuerzo y empeño se han prodigado por parte de los blancos en el oriente darán quizás un fruto amargo y envenenado. (Zig-Zag, febrero 1908)

En este párrafo es evidente la concepción del imperio chino como "no civilizado" y que sólo gracias a los avances tecnológicos europeos logrará levantarse e incluso convertirse en una amenaza futura. Indudablemente la concepción de civilización que se articula al referirse al "Imperio Celeste" y que en variados artículos en las revistas que analizamos se menciona, resulta similar al discurso que los mismos chilenos construían en torno a su propia modernización, en contraste, entre otros, a los pueblos indígenas. Además de las obvias diferencias socioculturales entre lo que sucedía en América y China, es notable la fuerza de la retórica del "ser occidental" que imperaba en el lenguaje latinoamericano de aquel entonces. Como lo señala Mignolo, y considerando la época en la que nos atañe, América Latina va redefiniendo las relaciones con Europa, elaborando un discurso de la "identidad Latinoamericana". Para la comunidad intelectual de la región, el cruce y superposición de poderes imperiales se concibió no tanto en términos de colonización sino de occidentalización :

La cosificación del concepto de cultura, y la gestación de entes como las culturas nacionales (continentales o subcontinentales) fue y es una parte integral de la idea misma de occidentalismo, de la construcción de occidente como el sí-mismo y del resto del planeta como la otredad (Mignolo, 1998, p.28).

Al texto sobre la locomotora lo acompaña una fotografía del tren cruzando entre las ruinas de la Muralla China, símbolo de esa civilización. Si bien las caricaturas continuarán cumpliendo un papel fundamental, la incorporación de fotografías adquiere una significancia para el público de las revistas magazinescas, pues serán las primeras imágenes que se obtendrá de países tan lejanos como China. La introducción y difusión de la fotografía sintoniza con los procesos globalizadores y a su vez de acercamiento del mundo que supone la expansión del capitalismo. Aunque ya se había hecho extensa en los periódicos del país, la fotografía en las revistas magazinescas tendrá un gran impacto en la sociedad chilena (Ossandón y Santa Cruz, 2005, p.70). Ahora bien, será el modo en que se relate esa imagen el que finalmente entregará el mensaje al público lector, pues si consideramos el ejemplo anterior, la bajada de pie de la fotografía de la locomotora podría haber sido "los avances tecnológicos occidentales destruyen los muros de la majestuosa y milenaria muralla china", no obstante, el mensaje fue precisamente lo contrario. 
De esto último se deduce que no es China la que entra a través de la fotografía, sino “...aquella forma o lenguaje (gloria de nuestra época y terror para nuestros ojos, se dijo de la fotografía en sus inicios) a través del cual un mundo a la vez ancho y constreñido se hace posible o visible" (Ossandón y Santa Cruz, 2005, p.70-71). Y en la descripción de la fotografía es donde encontramos la evaluación sobre una China "atrasada" que adopta avances (la locomotora, en este caso) que la encaminan hacia la civilización; aún más, es precisamente la adopción de esa tecnología la que la constituye, al menos en el discurso del pie de foto, en una amenaza futura.

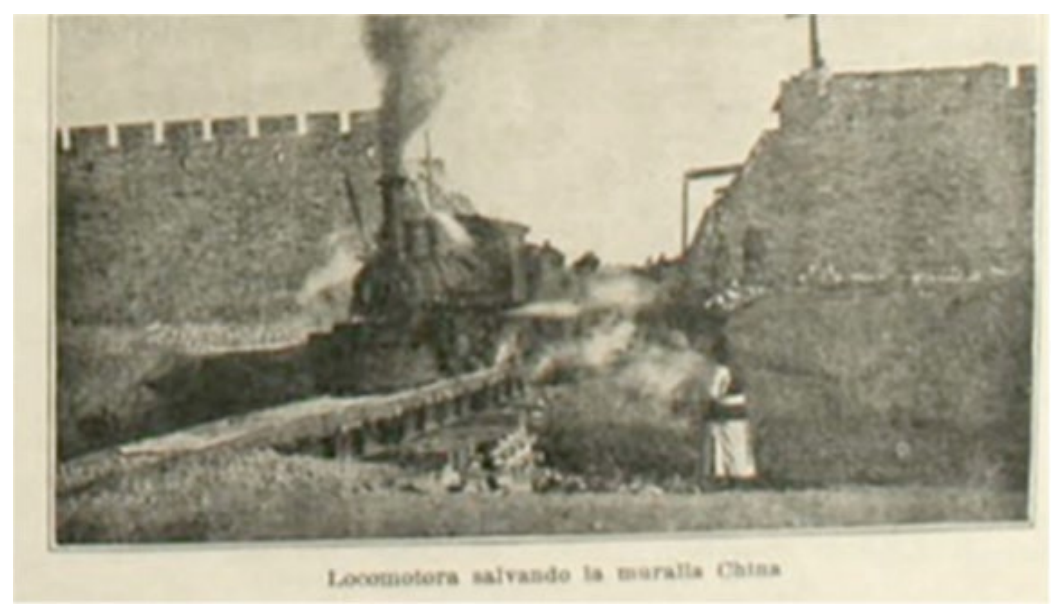

Zig-Zag, 16 de febrero de 1908.

Variadas serán las noticias o relatos acerca de los beneficios que tendrá la población china con la influencia occidental, muchas de las cuales serán ilustradas con fotografías. Destaca, por ejemplo, la creación de cárceles: "La cárcel municipal de Pekín, en efecto, es una de las mejores pruebas de las tendencias progresistas de la China moderna..." (Sucesos, 28 de septiembre de 1916); el raid de automóviles entre Pekín y París que se llevó a cabo en 1906, como un gran suceso para el pueblo chino (Sucesos, 10 de octubre de 1907); el despertar de la China que se ocupa de modernizar su ejército y desarrollar costumbres europeas (Zig-Zag, 6 de enero de 1907) o los progresos de la China bajo las y los maestros europeos/as en la escuela para ciegos y la escuela de medicina (Zig-Zag, 18 de noviembre, de 1909). En estos ejemplos podemos observar una mirada positiva hacia China en relación con los procesos de modernización y cambios sociales que son considerados avances para la sociedad.

A pesar de ello, la tendencia de noticias o relatos hacia los cambios sociales de China conviven con una mirada negativa que se alimenta de descripciones de desprecio, incluyendo referencias a la suciedad, consumo de todo tipo de especies de animales, violencia o castigos. Otros relatos, bajo el título de "curiosidades", también enfatizan el aspecto de un ser esencial chino, caracterizado por un tipo de comportamiento o costumbres extrañas. En ellas hallamos, por ejemplo, textos que se refieren a la forma de los "ojos chinos" y su diferencia con los de "la raza blanca": "los ojos no se abren como los de nosotros (...) en los hombres de la raza blanca suele presentarse una oblicuidad positiva de los ojos y que nosotros no lo notamos" (Zig-Zag, 6 de enero de 1907); "el fanatismo chino" en el que describe todo tipo de 
autoflagelaciones que serían prácticas religiosas (Zig-Zag, 7 de abril de 1907), la medicina china, donde destacan los ingredientes como el vidrio molido, la grasa de serpiente o la sangre de tigre (Zig-Zag, 20 de mayo de 1908) o los pies vendados de las chinas (Sucesos, 28 de julio de 1910). Esto se combina con otros relatos culturales que si bien no dejan de llamar a la curiosidad del chileno, describen aspectos de la vida cotidiana, como la familia y el habitar de generaciones bajo un mismo techo (Sucesos, 23 de agosto de 1917), los inventos como la taquigrafía para el lenguaje chino (Sucesos, 20 de septiembre de 1917), el pelo postizo traído de China (Sucesos, 7 de junio de 1917), ropa interior para los soldados franceses hecha de papel chino (Sucesos, 10 de mayo de 1917) o el secreto chino del arte del capullo en bronce, plata u otro (Sucesos, 28 de diciembre de 1916).

Las curiosidades se combinan con el misticismo oriental que una y otra vez vuelve a decorar el imaginario dual y contextual de lo chino. En estos textos abundan el adjetivo "misterioso" y entre los variados relatos se destaca un cuento del escritor chileno, Sady Zañartu, que se titula "En el país de Fu-Sang” y se publicó en la revista Zig-Zag el 22 de agosto de 1925 y que combina diversos aspectos referentes a lo "oriental". El cuento, ambientado en las calles de la ciudad peruana Tacna, relata la historia de un misterioso "misionero" (budista) chino de nombre Juan Shin. El misionero había sido salvado de cumplir castigo por el crimen de asesinar mujeres, gracias a que el Buda lo salva milagrosamente por considerarlo su hijo predilecto. La historia combina elementos del misticismo orientalista de actos de violencia entre la invención de ritos, decorada con la estética de espacios chinos, con faroles rojos, aroma a opio, luces tenues y sombras de siluetas. El cuento de Zañartu evidencia los aspectos señalados acerca del imaginario chino de la época, incluyendo referencias a prácticas religiosas ficticias, creando una historia en el que el asesinato de mujeres responde a actos de sacrificio al Buda.

\section{Guerra sino-japonesa}

Las características ya señaladas serán una constante. Al igual que la llegada de la República y la aspiración de una China moderna, los acontecimientos históricos del periodo también marcarán la tendencia de las noticias y relatos que hallaremos en las revistas. Posterior a la tercera década del siglo XX, la guerra sino-japonesa, que se inicia en 1937, será la pauta que marcará las notas sobre China. Una serie de fotografías y noticias al respecto estarán una y otra vez presentes. La tendencia será una serie de fotografías de la guerra, retratando las batallas y terribles actos de los japoneses en China, elevando el discurso de apoyo a la China republicana; algo que también se puede observar en otros medios de prensa en Chile (ver Palma y Montt Strabucchi, 2017). Entre las diversas noticias que llegan del exterior y son plasmadas en las revistas magazinescas, encontramos uno de los textos más extensos en que se eleva la imagen de la cultura ancestral, en las palabras de quien fue el escritor chino más conocido de la época, Lin Yutang. El texto se publica entre septiembre y octubre de 1937, en plenos ataques de los japoneses a la ciudad de Peiping (Beijing) y Shanghai. Lin Yutang describe la belleza de la ciudad de Peiping, como "una de las joyas que encierra el universo. (...) Peiping es magnánima, en ella se refugia lo antiguo y lo moderno, sin que por ello cambie su aspecto (Zig-Zag, 1937). En su texto, el escritor describe una ciudad cosmopolita, donde las 
costumbres ancestrales y tradiciones de la antigua china dialogan y comparten los espacios con el mundo moderno, la influencia de la cultura occidental y las nuevas estéticas que se perciben en las vestimentas y gustos de sus transeúntes:

Ciudad soñada por los reyes, con sus palacios y jardines cubiertos de perfumadas flores, avenidas amplias y kilométricas, museos de arte, colegios, universidades, hospitales, templos, pagodas y calles llenas de tiendas de objetos de arte chino, anticuarios y libros usados. Peiping se asemeja al paraíso de un "gourmet" con sus restaurantes que datan de siglos, atendidos por chinos de cabeza afeitada, los hombros cubiertos por una toalla, y que han sabido conservar la perfecta cortesía tradicional del tiempo del imperio, cuando servían a los poderosos mandarines (Zig-Zag, № 1696, septiembre-octubre, 1937).

El texto de Lin Yutang describe una Peiping que más que una ciudad asiática, pareciera una ciudad europea; es decir, es una descripción que acerca a una estética más europeizada de la capital china, que la hace más cercana y, por lo tanto, más atractiva para el público lector chileno. Si bien incluye los elementos asiáticos, su descripción la decora con una atmósfera como si se estuviera recorriendo los paseos de los Champs Elysées en París. Algo así como la chinoiserie trasladada al imaginario de una ciudad. Carlos Bos, quien era el director de la Aduana en China, también deleita a los lectores con un texto que se publicó en Zig-Zag entre noviembre y diciembre de 1937 (№ 1702), en medio de las noticias bélicas. En el texto, Bos alude a la "aguda jovialidad" del pueblo chino: "Se eleva sutil y fina como el humo azul de un cigarrillo. Obedece al ritmo lento de lo oriental y, a través de ella, siempre está presente un sentimiento delicado de urbanidad”. A esta descripción fina y estética de la población china, Bos añade variadas alabanzas en que eleva el carácter y el comportamiento de las personas chinas igual o incluso superior que las de occidente. Lo que es ya de suponer, el elemento orientalista que, como ya señalábamos, decora el escenario de manera transversal en estos distintos periodos históricos, no faltará en las descripciones, destacando el aspecto de admiración a las invenciones e ingenio de las personas chinas, a la paciencia y elevando a la figura de las y los campesinos, quienes fueron los que sostuvieron el país, a pesar de las desigualdades que se vivían en el periodo imperial:

Los campesinos... A su paciencia y su determinación de vivir, aparentemente infinitas, debe en lo absoluto la nación el haber sobrevivido. A pesar de las incursiones de bandidos, en que han muerto por centenas de millares, a pesar de impuestos exorbitantes y de exacciones, de inundaciones, de hambres y epidemias, ellos resisten, viven, perdura. En ellos vive China. (Zig-Zag, 1937, № 1702).

Sobre la guerra y sus enfrentamientos, destacan las narraciones y fotografías desesperanzadoras de la guerra, animando a que ambos pueblos logren la paz:

Chile conserva por la bizarra nación China, una laudable y sincera amistad, y en estos momentos de dura prueba para ella hay en el corazón de cada chileno el ferviente deseo de que pronto termine la sangrienta guerra, en la cual están empeñadas dos pueblos que, 
por muchos conceptos, se han hecho acreedores a la estimación y al respeto nuestros. (Zig-Zag, № 1698, septiembre-octubre, 1937).

El llamado a que China logre salir de la situación bélica con Japón, a apoyar y admirar a aquella nación republicana, que había logrado terminar siglos de imperialismo que, con figuras como Hu Shih (que Bos también menciona en su texto), ansiaba una modernización occidentalizada de la "Celeste República" (ZigZag, 5 de febrero de 1937), nubla, momentáneamente todo rechazo, actitud racista, desprecio y reacciones negativas vistas en el pasado. Una vez más el contexto histórico - político, alimentado por la mirada de occidente, será el que indicará la pauta de las noticias que se publicarán en las revistas.

Si bien hay distinción geopolítica de dos países en conflicto, se observan también discursos sobre "la violencia oriental" en que esa división entre los sujetos chinos y japoneses se vuelve porosa. También en Zig-Zag de 1937 hallamos un texto del primer ministro británico, David Lloyd George. El ministro se refiere a los exterminios realizados por el pueblo japonés:

La situación chino-japonesa es una versión modernizada y brutal de la fábula del lobo y el cordero. El lobo, ávido de carne de cordero, echa la culpa de la catástrofe a la infeliz víctima. Pero se nota la característica oriental en los métodos de tortura empleados en la destrucción de la presa indefensa. El programa es ir cortando el cuerpo pedazo a pedazo (Zig-Zag, 1937).

Efectivamente, la violencia por parte de Japón en la guerra ha sido uno de los eventos más trágicos descritos a lo largo de la historia del siglo XX en China (Yoshida, 2006). Sin quitar el carácter negativo y brutal de esos actos, en este párrafo hay una palabra que adquiere una connotación que va más allá de lo japonés; nos referimos al término de "oriental”. Lloyd-George, al utilizar ese concepto amplía la violencia utilizada en la guerra a actos que serían comunes en los pueblos asiáticos. Ahora bien, en el texto de "Semanitas", señalado arriba, se considera a lo japonés (en este caso el idioma) como lo mismo o parte de lo chino, sin distinción. Considerando esta no distinción entre dos personas de dos culturas distintas, como sucede con lo chino y lo japonés, la utilización de la frase "la violencia oriental" en el escrito de Lloyd-Georg, permite acercarnos a la idea de "suplicio chino" como un símil. Esto último, principalmente, por el énfasis hacia los castigos chinos descritos durante este periodo y la porosidad entre los pueblos del este asiático como lo mismo, como "chinos" o "lo chino", independiente de su origen.

Estas concepciones de un imaginario hacia lo chino que tiene relación con la agresividad (no olvidemos el quique) y la violencia se suma a los otros elementos, racismo, amenaza, suciedad, misticismo, orientalismo, que seguirán decorando el escenario político de la época. Aunque la revista Sucesos deja de publicarse en 1932, Zig-Zag continuará hasta 1964, en la cual se manifestarán otros elementos vinculados al establecimiento de la República Popular China y la figura de Mao Zedong. En un contexto marcado por la Guerra Fría, se agregarán nuevos factores a la representación de China para la segunda mitad del siglo XX. 


\section{Conclusiones}

Ahmed señala que cada encuentro reabre los encuentros pasados: "El encuentro cara a cara no es entre dos sujetos iguales y en armonía; el encuentro es antagónico" (Ahmed, 2000, p.8, traducción propia). Aunque el papel que la República Popular China ha adquirido como segunda potencia global, la pandemia de 2020, cuyo comienzo se rastrea (a la fecha de esta publicación) a Wuhan y se extiende al mundo, ha levantado nuevamente los imaginarios del pasado que se guardan en la memoria chilena. A pesar de los cambios políticos, económicos y geopolíticos, como también de la deconstrucción de los estereotipos que es posible vislumbrar sobre todo en el mundo artístico, aún es posible observar una continuidad de representaciones o visiones racistas y esencialistas con respecto a la noción de amenaza/poder potencial que China representa, que no se alejan demasiado de los imaginarios de las revistas magazinescas aquí abordadas.

Desde esta perspectiva, las revistas magazinescas que surgen a principios de siglo XX, en pleno desarrollo de la modernización del país, de la opinión pública y de reflexión en torno a la identidad chilena, transmiten el encuentro "imaginario" por medio de sus imágenes y narraciones contribuyendo al imaginario de lo chino, pues el encuentro directo era mucho menor que el alcance que tuvieron las revistas en la sociedad. Este imaginario, alimentado por los estereotipos del "peligro amarillo", orientalismo, racismo, amenaza, suciedad, misticismo y porosidad de lo chino como lo oriental (y luego "lo asiático"), sigue apareciendo en el imaginario chileno. En este contexto, la dinámica entre lo circunstancial versus el imaginario es fundamental para el conflicto de ese encuentro, pues si bien hablamos de imaginarios que están presentes en la memoria de la mayoría de la población chilena, su explosión surge a partir de la epidemia y a propósito de la guerra comercial china con Estados Unidos, país que vuelve a levantar la imagen del "peligro amarillo" en un contexto histórico completamente distinto. Sobre Chile, a pesar de algunas visiones radicales o alternativas, la persistencia de estos tropos racistas de la alteridad aún debe ser interrogada y problematizada para que no perduren en el tiempo y en futuras situaciones de crisis y conflicto como lo que se ha observado en épocas de pandemia. A pesar de una relación comercial sólida con el país asiático, se observa que su sociedad aún guarda ese imaginario en su memoria, lanzando todo tipo de anuncios, caricaturas, acciones y comentarios que recuerdan al Chile de hace más de cien años, sosteniendo la continuidad de ideas sobre "la otredad" e identidad etnonacional chilena. 


\section{Referencias bibliográficas}

Ahmed, S. (2000). Strange Encounters: Embodied Others in Post-Coloniality. Routledge.

Cano, V. y Soffia, M. (2009). Conocer para legislar y hacer política: los desafíos de Chile ante un nuevo escenario migratorio. CEPAL, Serie Población y desarrollo № 88.

Chan, C. y Gómez, N. (2020, 27 de junio). Racismo, televisión y publicidad. El Mostrador. https://m.elmostrador.cl/noticias/opinion/columnas/2020/06/27/ racismo-television-y-publicidad-en-chile/

Chan, C. y Montt Strabucchi, M. (2020a). Questioning the Conditional Visibility of the Chinese. (Non) Normative Representations of China and Chineseness in Chilean Cultural Productions. Journal of Chinese Overseas, 90-116. https://doi.org/10.1163/17932548-12341414

Chan, C. y Montt Strabucchi, M. (2020b). Many-faced orientalism: racism and xenophobia in a time of the novel coronavirus in Chile. Asian Ethnicity, 1-21. https://doi.org/10.1080/14631369.2020.1795618

de Valdivia, V. (1929). El imperio iberoamericano. Nuestra colonización. Nuestro engrandecimiento. Nuestra participación en la cultura mundial. Editorial Hispanoamericana.

Dube, S. (2017). Mapas de la modernidad: disciplinas espacio-tiempo. Estudios de Asia y África, 52(3), 493-534. https://doi.org/10.24201/eaa.v52i3.2255

Dussaillant, J. y Urzúa, M. (Eds.) (2020). Concisa, original y vibrante. Lecturas sobre la revista Zig-Zag. Ediciones Universidad Finis Terrae.

Edwards, J. (1927, cuarta edición). El roto. Nascimento.

Feng, Y. (1995). From the imperial examination to the national college entrance examination: The dynamics of political centralism in China's educational enterprise. Journal of Contemporary China, 4(8), 28-56. http://www.tandfonline.com/loi/cjcc20

Herrera Styles, P. y Zamorano Pérez, P.E. (2019). Sorna, crítica y humor: el arte chileno visto desde la caricatura (1858-1910). Cuadernos de Arte de la Universidad de Granada, 50, 171-188. http://dx.doi.org/10.30827/caug.v50i0.11277

Hu-Dehart, E. (1994). Chinese Coolie Labor in Cuba in the Nineteenth Century: Free Labor of Neoslavery. Contributions in Black Stuides, 12(5), 38-54. https://scholarworks.umass.edu/cibs/vol12/iss1/5 
Isin, E. (2012). Citizenship after orientalism: an unfinished project. Citizenship studies, 1(5-6), 563-572. https://doi.org/10.1080/13621025.2012.698480

López, K. (2016). The Asian Presence in Mestizo Nations: A Response. En Y. Martínez-San Miguel, B. Sifuentes-Jáuregui y M. Belausteguigoitia (Eds.), Critical Terms in Caribbean and Latin American Thought pp. 125-131. Palgrave Macmillan.

Marchetti, G. (1993). Romance and the "Yellow Peril". Race, Sex, and Discursive Strategies in Hollywood Fiction. University of California Press.

Mejías Alonso, A. y Clemente San Román, Y. (2018). Instantáneas, una revista modernista en el Santiago de Chile de 1900. Revista General de Información y Documentación, 28(2), 579-591.

Mignolo, W.D. (1998). Postoccidentalismo: El argumento desde América Latina. En S. Castro-Gómez y E. Mendieta (Eds), Teoría sin disciplina (latinoamericanismo, poscolonialidad y globalización en debate), pp. 26-49. http://people.duke. edu/ wmignolo/InteractiveCV/Publications/Teoriassindisciplina.pdf

Mignolo, W.D. (2003 [1995]). The darker side of the renaissance: literacy, territoriality, and colonization, segunda edición. The University of Michigan Press.

Min, W. (2020). Mis Chinos, Tus Chinos: The Orientalism of Chilean K-pop fans. International Communication Gazette, pp. 1-19. https://doi.org/10.1177/1748048520928254

Montt Strabucchi, M. (2017). Imagining China in Contemporary Latin American Literature [thesis for the degree of Doctor of Philosophy, University of Manchester].

Revista Instantáneas (1900).

Sucesos (1903, 3 de octubre).

Sucesos (1907, 10 de octubre).

Sucesos (1916, 28 de diciembre ).

Sucesos (1917, 23 de agosto).

Sucesos (1917, 20 de septiembre ).

Sucesos (1917, 7 de junio ).

Sucesos (1917, 10 de mayo ). 
Ossandón, C. y Santa Cruz, E. Con la colaboración de Ávila, P. y Santa Cruz Grau, L.E. (2005). El estallido de las formas. Chile en los albores de la "cultura de masas". LOM, Universidad Arcis.

Palacios, N. (1904, 1918, segunda edición). Raza Chilena. Libro escrito por un chileno y para los chilenos. Editorial Chilena.

Palma, P. y Montt Strabucchi, M. (2017). La diáspora china en lquique y su rol en la política de ultramar durante la República y el inicio de la guerra fría. Diálogo andino, 54, pp. 143-152.

Palma, P. y Ragas, J. (2018). Enclaves sanitarios: higiene, epidemias y salud en el Barrio chino de Lima, 1880-1910, Anuario Colombiano de Historia Social y de la Cultura, 45(1), 159-190

Real Academia Española (2019). Disponible en www.rae.es

Rinke, S. (2002). Cultura de masas: reforma y nacionalismo en Chile 1910-1931. Dirección de Bibliotecas, Archivos y Museos.

Rojas Flores, J. y García Castro, M. (2014). Humor, magia y política en un diario conservador: el caso de Chu Man-Fú en El Diario Ilustrado, 1938-1950. Mapocho 76, 219-42.

Segato, R. (2007). La Nación y sus Otros. Raza, etnicidad y diversidad religiosa en tiempo de Políticas de Identidad. (1ae ed.). Prometeo.

Silva, B. (2008). Identidad y Nación entre dos siglos. Patria Vieja, Centenario y Bicentenario. LOM ediciones.

Silva, B. (2018). La espacialidad y el paisaje en las representaciones nacionales durante el Frente Popular Chileno. 1938-1941. Revista de Historia Social y de las Mentalidades, 22(1), 129-153. http://www.revistas.usach.cl/ojs/index.php/ historiasocial/article/view/3294/26002635

Siu, L. C. D. (2007). Memories of a Future Home: Diasporic Citizenship of Chinese in Panama. Stanford University Press.

Seijas, T. (2015). Asian Slaves in Colonial Mexico. Cambridge University Press.

Stang, F. y Solano, V. (2017). El escozor de la alteridad: un análisis sobre la construcción mediática del migrante colombiano en la televisión chilena. Revista Trabajo Social, 92, 1-13. https://doi.org/10.7764/rts.92.1-13

Wang, S., Chen, X., Li, Y., Luu, Ch., Yan, R. y Madrisotti, F. (2020). 'I'm more afraid of racism than of the virus!': racism awareness and resistance among Chinese 
migrants and their descendants in France during the Covid-19 pandemic. European Societies. https://doi.org/10.1080/14616696.2020.1836384

Yoshida, T. (2006). The Making of the "'Rape of Nanking": History and Memory in Japan, China, and the United States. Oxford University Press.

Zig-Zag (1907, 6 de enero).

Zig-Zag (1907, 12 de mayo).

Zig-Zag (1908, febrero).

Zig-Zag (1908, 20 de mayo).

Zig-Zag (1909, 31 de junio).

Zig-Zag (1909, 18 de noviembre).

Zig-Zag (1911, 23 de septiembre).

Zig-Zag (1911, 30 de diciembre).

Zig-Zag (1912, 13 de abril).

Zig-Zag (1917, 23 de agosto).

Zigzag (1925, 22 de agosto).

Zig-Zag (1937, 5 de febrero).

Consulta de Revistas en Biblioteca Nacional, Santiago, Chile:

Revista Zig-Zag, 1907, 1908, 1909, 1911, 1912, 1917, 1925, 1937

Revista Sucesos, 1907, 1916, 1917. 